\title{
ROSANA PAULINO: ARTE, CRÍTICA, SUBJETIVIDADE
}

\section{Gustavo Dionisio' \\ Gisele Sugawara²}

Resumo: Visamos abordar questões relacionadas aetnicidade e gênero na produção de arte contemporânea no Brasil tomando como exemplo certas obras de Rosana Paulino (1967) que, particularmente, tematiza tais problemáticas ao tecer duras críticas ao racismo e ao machismo cotidianos. Trata-se de significativa valorização da poética afro-brasileira, assim como um resgate da história das mulheres negras no Brasil. Surge, tendo em vista que o campo da arte é produtor de subjetividade, uma forma de fazê-la atrelada ao feminismo e antirracismo, isto é, toda uma dimensão necessariamente ético-política que ronda as criações da artista.

Palavras-chave: arte afro-brasileira; subjetividade; etnicidade.

Abstract: This article addresses certain issues related to ethnicity and gender on Brazil's contemporary art production; for this purpose, we used as examples RosanaPaulino's (1967) works of art because they summarize these issues while criticize daily racism and gender inequality. The artist's work regards a large appreciation of African-Brazilian forms of poetry, so as a necessary rescue of black women's history in Brazil. Through the essay a debate about a form of making art that is bounded to the feminist and antiracism political views and goals emerges, by being aware that the Art's domain is a producer of subjectivities. There is, therefore, a whole ethical-political dimension that surrounds Paulino's works, causing her themes to be extremely relevant to the current brazilian art circuit.

Keywords: African-Brazilian art, subjectivity, ethnicity.

\section{Arte, gênero e etnicidade}

É notório que no mundo das artes os nomes mais conhecidos são de homens, e há muito se questiona essa predominância; como se sabe, as mulheres apenas ganhariam um espaço mais significativo nesse meio somente com a terceira onda do movimento feminista da década de 1960. Em vista desta tradição patriarcal, em sua grande maioria não eram consideradas aptas para se inserir no meio artístico como criadoras propriamente ditas, mas apenas como musas inspiradoras. Ao final da década de 60, no entanto, os estudos de gênero viriam a proporcionar às mulheres uma maior liberdade para sair do espaço doméstico e conquistar outros, dentre eles o artístico.

\footnotetext{
1 Professor Assistente do Departamento de Psicologia Clínica da Unesp-Assis. E-mail: gustavohdionisio@gmail.com.

$2 \quad$ Universidade Estadual de São Paulo/UNESP-Assis. E-mail: giseletiemi93@gmail.com.
} 
Como propõe Judith Butler (2003, p. 28-29), o gênero pode ser entendido como uma categoria identificatória cujo estatuto é senão fabricado pela sociedade:

gênero pode ser compreendido como um significado assumido por um corpo (já) diferenciado sexualmente; contudo, mesmo assim esse significado só existe em relação a outro significado oposto... Como fenômeno inconstante e contextual, o gênero não denota um ser substantivo, mas um ponto relativo de convergência entre conjuntos específicos de relações, cultural e historicamente convergentes.

A partir dos anos 1980, o feminismo passou a ampliar ainda mais o debate sobre a identidade sexual a partir de teorias construtivistas, em que o gênero também é interpretado como processo cultural. Para Reckitt e Phelan (2006, apud TVARDOVSKAS, 2012, p. 134) foi também durante esse período que "a nova geração de afro-americanas e a arte negra feminista inglesa exploraram a intersecção entre as identidades racial e sexual e os legados do colonialismo e chamaram atenção para a dominação da mulher branca dentro do feminismo".

No campo das artes, é possivel perceber, de lá para cá, o quanto essa discussão sobre gênero é atuante na contestação da preponderância do sexo masculino dentro do circuito, denunciando uma misoginia latente que, a bem da verdade, não se aplica somente a essa área, mas à esfera do trabalho em geral. Trizoli (2008), por exemplo, acredita que toda essa movimentação que teve início nos anos 60 permitiu que uma arte mais politizada fosse ganhando corpo no decorrer das décadas seguintes. É patente, nesse sentido, que nos anos 70 víssemos surgir - Feminist Art Program no California Institute of Art, de Judy Chicago e Miriam Schapiro, cujo programa possibilitara o avanço no estudo de teorias ligadas ao feminismo dentro das universidades e, com isso, tornou mais "intima" a relação destas reflexões com o espaço de produção artística:

\begin{abstract}
A arte feminista é pluralista, não sendo, portanto, aconselhável dizer arte feminista, mas artes feministas, em que a valorização das diferenças na subjetividade de seus artífices e espectadores é elemento primordial para sua subsistência. Mesmo com as críticas ao racismo interno, e algumas desavenças de aspecto ideológico e teórico, o discurso principal desse grupo reafirma a existência inata das diferenças do sujeito artista ou do sujeito representado, colocando em cheque o ideal de sujeito universal, ou melhor, a subjetividade artística universal, que aceitava em seus parâmetros apenas homens brancos dotados da "genialidade". (TRIZOLI, 2008, p. 1503).
\end{abstract}

Posto isso, é possivel afirmar que a arte contém, em si mesma, uma dimensão ético-estético-política que carrega influência bastante significativa da história autobiográfica do/da artista como pano de fundo de seu trabalho. Possui esta 
dimensão ética na medida em que ocorre uma "escuta" da diferença que há no artista, ou seja, o criador afirmaria, assim, seu devir com base nessas diferenças. Também possui um caráter estético porque a arte é criação, ela não se fixa em um saber/lugar já estabelecido, sendo então "criação que encarna as marcas no corpo do pensamento" (ROLNIK, 1993, p. 7); por fim, a arte é também política porque consiste em um modo de combater certas forças, que, por vezes, bloqueiam as possibilidades do devir, que não nos permitem experimentar o estranho. Para Rolnik (2008), "o estranhamento constitui uma experiência crucial porque é a expressão sensivel das forças da alteridade em nosso corpo, que colapsam a cartografia vigente e nos levam a criar; sua anestesia significa, portanto, o bloqueio da potência crítica que caracteriza fundamentalmente a ação artística" (p. 3).

Nesta perspectiva apresentamos algumas obras da artista brasileira Rosana Paulino (São Paulo, SP, 1967), que desenvolve formas de fazer arte por meio de escultura-objeto, escrita-gravura, fotografia-pintura e instalação-performance, normalmente utilizando objetos típicos do cotidiano, como fotografias de família, almofadas, linhas de costura etc., tendo em vista a problemática da crítica étnicoracial e de gênero contida invariavelmente em seus trabalhos. A proposta consiste, portanto, em demonstrar como a obra de Paulino, artista negra e declaradamente feminista, é potente em questionar "verdades" postas como universais, tais como a contestação da noção de feminilidade e docilidade entendidas como inerentes à mulher. Suas obras são inovadoras na medida em que criam algo novo no campo do imaginário e do simbólico, carregando consigo um modo plural de criação que rompe inclusive com os limites dos gêneros artísticos (TVARDOVSKAS, 2013).

Sobre a questão da etnicidade, de acordo com Tvardovskas (2012), o debate sobre a produção artística que trata sobre o racismo tem pouquíssimo destaque em nosso país; contudo, é possivel observarmos algumas exceções, como as exposições "Rosa e Marrom: gênero e identidade racial na arte contemporânea", que ocorreu no Centro Cultural Afro-Brasileira "Odete dos Santos" em São Carlos (2007), na qual foram apresentadas artistas negras que não eram conhecidas no mercado formal de arte; e ao lado desta a exposição "Réplica e Rebeldia", que aconteceu no Centro Cultural Banco do Brasil de Brasilia também em 2007, e exibiu obras de artistas africanos e afro-brasileiros - aí incluídas algumas obras da própria Rosana Paulino.

Além dessas exposições, a autora também cita duas artistas que dialogam com a temática da marginalização social e do racismo: Rosângela Rennó (1962, MG) e Rosana Palayzan (1963, SP). Elas utilizam imagens da população marginalizada, a qual é composta, em sua maioria, por negros, para desenvolver uma crítica diante da violência que vivenciam. É válido pontuar que esse tipo de arte, vinculada com - Movimento Negro ou o Movimento Feminista Negro, pode ser disparadora de debate e de uma crítica importante acerca do racismo no país, assim como pode ser também uma forma de contestação perante o falocentrismo e o 
etnocentrismo (sobretudo europeu, no caso) vigentes.

Para Sampaio (2015), esse tema da etnicidade se manifesta de forma evidente nas obras de Paulino e de outros artistas negros como Paulo Nazareth e Jaime Lauriano. Suas obras nos trazem a problemática real do negro no Brasil hoje, isto é, não há uma tentativa de falar somente sobre mestiçagem ou um tipo caricato, como o negro da lavoura por exemplo. Estes artistas produzem uma provocação direta ao espectador, é um convite ao debate.

O discurso difundido de que não há negros no Brasil, que o que temos são mestiços, que não existe preconceito racial, e por isso não há a necessidade de discutirmos tais assuntos nesse país são exemplos que se perpetuam pela fala do opressor. $O$ trabalho desenvolvido por esses artistas, principalmente dentro de um meio historicamente elitizado e branco, é fundamental para que esse discurso de esquecimento não seja reproduzido. Os artistas negros aqui mostrados colocam a discussão racial em pauta na arte contemporânea e especificamente na arte brasileira. (SAMPAIO, 2015, p. 1309).

\section{Tecendo Sentidos com Rosana Paulino}

As obras de Paulino possuem uma ligação muito forte com a cultura africana e com o lugar que a mulher negra ocupa historicamente na sociedade. $\bigcirc$ racismo e a violência ganham cor e textura em suas obras, de tal modo que os corpos femininos recebem formas inusitadas, capazes de tirar o "espectador" do lugar habitual em que se encontra, isto é: sua obra causa uma verdadeira desterritorialização da imagem corporal, uma espécie de "devir outro corpo", na esteira do pensamento de Deleuze e Guattari (1997).

Sobre a trajetória de Paulino no mundo artístico, Canton (2001, p. 89-90) afirma que:

No início de sua carreira, nos anos 90, Rosana Paulino realizava trabalhos que utilizavam imagens de mulheres e crianças negras. Serigrafados, pintados, recortados, costurados, os trabalhos se inserem numa discussão em que arte se articula com a política, raça e cultura, questões que, naquele começo de década, ainda não frequentavam a produção artística jovem de modo tão contundente. Manipulando a diferença na arte, Paulino expandiu suas "retratospectivas", que trabalhavam com antigos retratos familiares, falando de um universo negro e feminino, para lidar com novas instalações utilizando suportes originais.

Há uma memória física e psíquica que ronda suas obras: a reminiscência do corpo da negra no espaço doméstico (a empregada ou a ama de leite), objetos 
que retornam às suas raízes, como a agulha, a linha, tecidos que, inclusive, eram utilizados por sua mãe que costurava, produzem uma imagem fortemente crítica, uma imagem-crítica que faz a crítica da imagem (DIDI-HUBERMAN, 1998). Os elementos dos quais a artista se utiliza - tecidos, fitas, patuás etc. são aí ressignificados, ganhando uma dramaticidade que compõe o repertório de elementos que a artista emprega com uma finalidade especifica: fazer a denúncia de uma dominação específica e socialmente imposta, e que, para muitos, é vivida logo de antemão, como no caso da condição racial. Como seriam a vozes dessas mulheres negras? E como seria, enfim, o seu olhar?

Imagem 01- Imagem transferida sobre tecido, bastidor e linha de costura $30,0 \mathrm{~cm}$ diâmetro

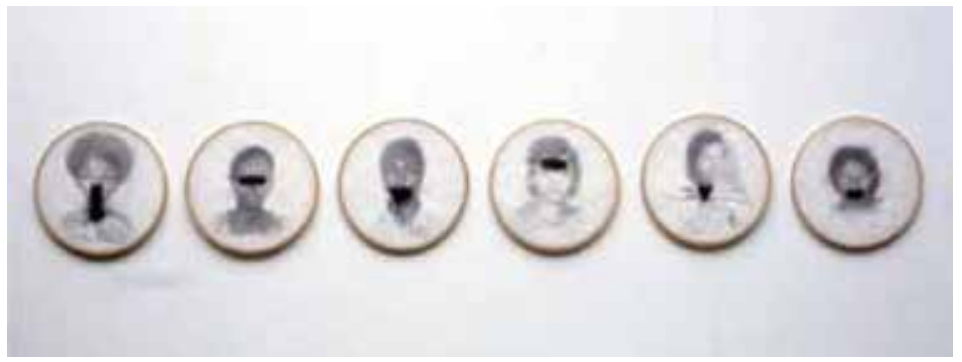

Fonte: Rosana Paulino, Bastidores (1997). Disponivel em <http://mam.org.br/artista/paulino-rosana/>.

\section{Bastidores}

Sobre suas obras em bordado, Paulino explica em sua tese como funciona o processo de modificação das imagens:

\footnotetext{
Linhas que modificam o sentido, costurando novos significados, transformando um objeto banal, ridículo, alterando-o, tornando-o um elemento de violência, de repressão. $\bigcirc$ fio que torce, puxa, modifica o formato do rosto, produzindo bocas que não gritam, dando nós na garganta. Olhos costurados, fechados para o mundo e, principalmente, para a condição no mundo. (PAULINO, 2011, p. 88).
}

Em Bastidores, Paulino (2011) valeu-se do xerox de fotos de mulheres negras, extraídas de álbuns fotográficos de sua familia, e as transferiu para tecido; em seguida, realiza uma costura da boca, dos olhos, da testa e garganta. Usa, para tanto, uma linha escura, e o ato de tecer é grosseiro, quase violento. Tais fotos, são em sua maioria no formato $3 X 4$, isto é, comuns em grande medida; a linha, no entanto, traz uma dramaticidade diferente à imagem, parecendo carregar toda a dor histórica e autobiográfica da artista. $O$ bordado agressivo dos fios nos leva a um incômodo que remete ao passado escravocrata não 
resolvido e ainda presente de alguma forma - presente, principalmente, nos corpos negros subjugados até hoje. Paulino manuseia a agulha de costura para se comunicar, para expor o sofrimento e não deixar esquecer a história dos negros e, sobretudo, das mulheres negras do Brasil.

Sua obra é cheia de metáforas a serem descobertas, tendo como pano de fundo o questionamento perante a situação dos afrodescendentes hoje, não somente sua condição social, mas também sobre seu corpo docilizado, capturado pelas mídias da sociedade de controle que idealizam uma imagem universal de beleza que não condiz com a beleza da mulher negra e seus cabelos "pixaim"; por outro lado, e talvez de maneira ainda mais cortante, suas obras também expressam uma vontade de desmistificar o corpo da mulher negra como corpo sexual, coisificado e servil.

O próprio título Bastidores já indicaria muito sobre a obra: parece se referir a algo que ocorre "atrás da cortina", em um ambiente doméstico, íntimo, isto é, lugar no qual a violência é escondida, mas não só: é também calada. Canton (2001, p. 89-90), por exemplo, afirma que a técnica utilizada por Paulino contrapõe "radicalmente o lado bucólico e delicado do bordado com a violência doméstica contra as mulheres".

A obra também pode ser interpretada como uma referência às mordaças que eram impostas aos escravos - também conhecida como "máscara de flandres" - para que eles não falassem, não bebessem, não comessem terra como tentativa de suicídio ou escondessem pepitas de ouro nas minas de carvão (TVARDOVSKAS, 2012). Ao nos remeter a essa forma de controle utilizada durante a escravidão, a artista nos mostra como essa crueldade persiste até hoje, mas de outro modo, isto é: como se sabe, o controle do corpo negro se dá por outras vias. A identidade da mulher negra, sua história e suas raízes the são retiradas, ela se torna apenas a doméstica ou o corpo que causa desejo, - que nos mostra de forma explícita que ainda há efeitos sintomáticos da violência vivenciada durante o período escravocrata, efeitos estes que podem ser entendidos como trauma. De acordo com Dionísio (2016, p. 206),

São experiências que de tão resistentes não morrem, legando aos
sobreviventes um luto impossivel a ultrapassar: assim como ocorre com o
trauma, a escravidão e a ditadura assombram a partir de um passado que
ganhará outra imagem, no presente de nossas vidas internas, sob a forma
da repetição. Violento, o trauma sempre exige alguma resposta aqui-agora.

No caso de Paulino sua resposta no aqui-agora veio por meio de sua arte, a qual traz consigo ressignificações de objetos e lugares, tais como as instalações que fez em antigas senzalas, seus bordados etc. Para Cristina Freire (2000) a 
“materialização dos projetos parte da ação do corpo do artista que [,] ao ressignificar os espaços, revela as espessuras simbólicas dos lugares e das coisas operando uma reordenação subjetiva de sentidos" (apud DIONÍSIO, 2016, p. 207)

Sobre o uso do bordado, ou seja, de algo entendido como "essencialmente" feminino, é possivel afirmar que foi o modo encontrado por Paulino para desconstruir objetos sexualizados, como explica Carvalho (2008): as referências de gênero aos objetos atuam como sentidos imanentes, ou seja, o sentido do objeto provém de práticas sociais e é na prática cotidiana que o gênero é atribuído ao objeto. Paulino, ao empregar a técnica do bordado e retirando toda sua dimensão de resignação, passividade e "feminilidade", transforma-o em algo diferente do gênero que the foi atribuído, de modo a se tornar manifestação de sofrimento e revolta. Talvez transforme-o em um simulacro, no sentido que Ulpiano (1989) atribui ao termo, na esteira de Baudrillard (1989/2015).

O pensamento do simulacro traz uma originalidade. A originalidade dele é que o simulacro é impossivel de ser relacionado a um modelo. Se é impossivel de relacioná-lo a um modelo, ele tem que sair da analogia de proporção. Não se pode trabalhar com analogia de proporção com ele. Por quê? Porque a analogia de proporção pressupõe a relação com o modelo [...] No mundo do simulacro, nada é cópia, porque tudo o que existe ganha a sua singularidade [...] ele se autonomiza, ganha uma independência... mascara o modelo!

Para Scott (2012, p. 347), o gênero não é um guia para categorizar estatísticas de identidade sexuada, mas para criar diálogo criativo entre "imaginação, regulação e transgressão nas sociedades e culturas que estudamos". E é isso que Paulino faz através de suas obras: ela cria uma ponte entre arte e política por meio de sua arte atravessada pelas teorias de gênero, pela sua militância feminista e sua origem negra. Assim, a desconstrução de objetos que foram "sexualizados" ao decorrer do tempo, isto é, que foram tidos como femininos, é um modo de escancarar a noção simplista que ainda regula a ideia de gênero como algo determinado biologicamente - mulher/homem, feminino/masculino.

Enquanto não podemos exatamente separar nossos corpos de nós mesmos, nós podemos cogitar a ideia de que corpos não são o suficiente para providenciar uma segura definição de identidade, papéis e orientação sexual. A ideia mais radical de entendimento de gênero é sobre a concepção de várias definições de homem/mulher, masculino/feminino, na sua complexidade e instabilidade. É sobre as lutas para manter os significados no lugar (impor e fazer cumprir as normas) e lutas para resistir ou derrubá-los. (SCOTT, 2012, p. 337). 
Imagem 02 - Série Bastidores, 1997, imagem transferida sobre tecido, bastidor e linha de costura, $30,0 \mathrm{~cm}$

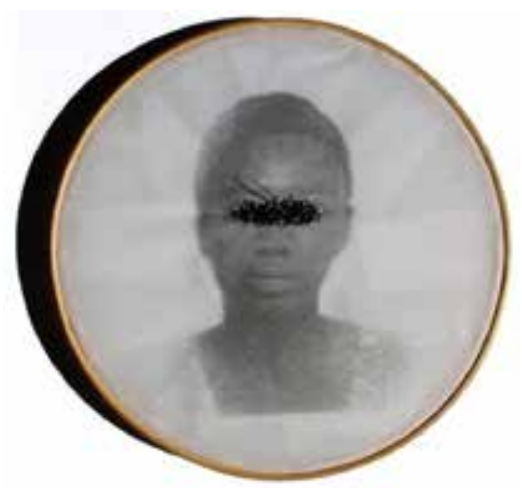

Fonte: Rosana Paulino, Bastidores (1997). Disponivel em <https:// www.ufrgs.br/arteversa/? $p=132>$.

\section{Ama de leite e outr'As amas}

Em sua série intitulada Ama de leite Paulino explora um uso diverso que foi feito do corpo da mulher negra nos séculos anteriores, a saber: analisa a relação complexa entre a ama de leite e o bebê que não pertence a ela. É um vínculo em que há contato intimo e totalmente atravessado por vetores afetivos, incluindo aí a situação concreta de submissão e servidão ${ }^{3}$. Ao explicar o que procurou investigar com a série, declara que sua intenção consistia em entender de que forma o corpo negro feminino se tornou importante no período escravocrata, tratado como algo útil e subserviente, e quais seriam as reverberações desse fenômeno na sociedade atual:

O projeto, iniciado alguns anos antes do início do mestrado através de desenhos e que posteriormente ganhou companhia de esculturas e instalações, procura investigar a importância das mulheres negras no período escravocrata bem como a herança que estas primeiras negras legaram não somente às negrodescendentes, mas também ao país. Ama de Leite despertou também minha atenção para as origens de uma ligação quase simbiótica entre o elemento negro feminino e a ocupação de um local social servil simbolizado pela passagem, no imaginário social, dos papeis de ama-de-leite à babá, da mucama à empregada doméstica ocupado, ainda hoje, pelas mulheres negras na sociedade brasileira. (PAULINO, 2011, p. 58). 
Ama de leite representa, em suma, a ligação muito próxima entre o corpo da negra e as posições sociais passageiras (passageiras pois os filhos de suas patroas cresciam, a ponto de deixar de ser ama de leite para retornar à condição de escrava) e servis a ela destinadas até hoje, como no caso de babás e empregadas domésticas, as quais, muitas vezes, perdem sua "maternidade", isto é, cuidam dos filhos de seus patrões e por isso não têm tempo para seus próprios filhos.

De acordo com a artista, esta série foi o embrião para a criação de diversas outras obras nesta linha de questionamento e, dentre elas, se destaca As Amas. Esta obra foi executada na senzala da Fazenda Mato Dentro (Campinas, SP), e a ideia de Paulino - ao se utilizar de um lugar como esse, já tão carregado de uma memória triste de nossa história -, era que sua arte pudesse dialogar com o espaço e, de algum modo, adquirir novas dimensões conceituais. Ela escreve:

De fato, a emoção despertada pelo "clima" da senzala não pode ser traduzida nas - embora belas - imagens fotográficas. Sentir o "ar" do espaço trabalhando conjuntamente com os elementos plásticos é sem dúvida nenhuma o grande diferencial deste projeto. $A$ isto foram acrescentados objetos possiveis de serem encontrados tanto na cultura popular quanto na religião Umbanda, da qual minha familia é praticante, ampliando os possiveis sentidos presentes na obra. Fita de cetim, imagens digitais (que já haviam sido trabalhados nas obras Amas de leite), e rosas brancas - flores muito utilizadas na Umbanda, onde representam a falange do chamado "Preto Velho" - foram os materiais empregados. Transformar estes elementos da cultura popular em uma obra de arte pulsante, em um lugar fortemente emblemático, eis a dificuldade maior desta obra. (PAULINO, 2011, p. 64).

Imagem 03 - As Amas. Instalação na Senzala da Fazenda Mato Dentro, Campinas, São Paulo. Fitas de cetim, cerâmica, papel machê, fotografia digital, vidros de relógio, parafina e pétalas de rosas brancas. Dimensão variável, 2009

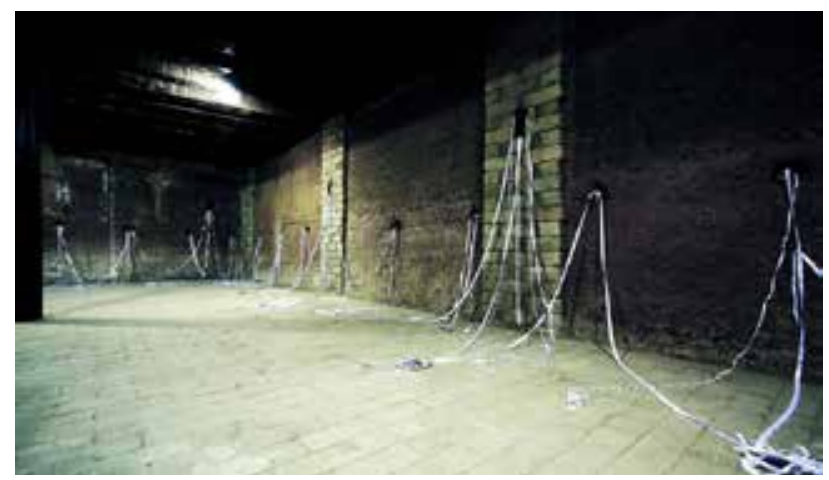

Fonte: Rosana Paulino, As Amas (2009) Disponivel em: <http://www.rosanapaulino. com.br/blog/tag/senzala/>. 
Imagem 04-Desenho da Série Tecelãs, 2003, grafite e aquarela sobre papel. $32,5 \times 25,0 \mathrm{~cm}$.

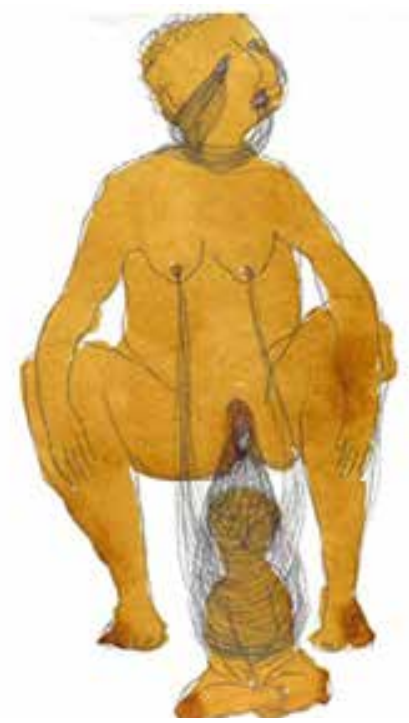

Fonte: Rosana Paulino, Tecelãs (2003) Disponivel em <http:// www.rosanapaulino.com.br/blog/falta-de-desenho/>.

Imagem 05 - Ama de Leite n. 1, 2005, terracota, plástico e tecido, 32×17,5×8,2 cm

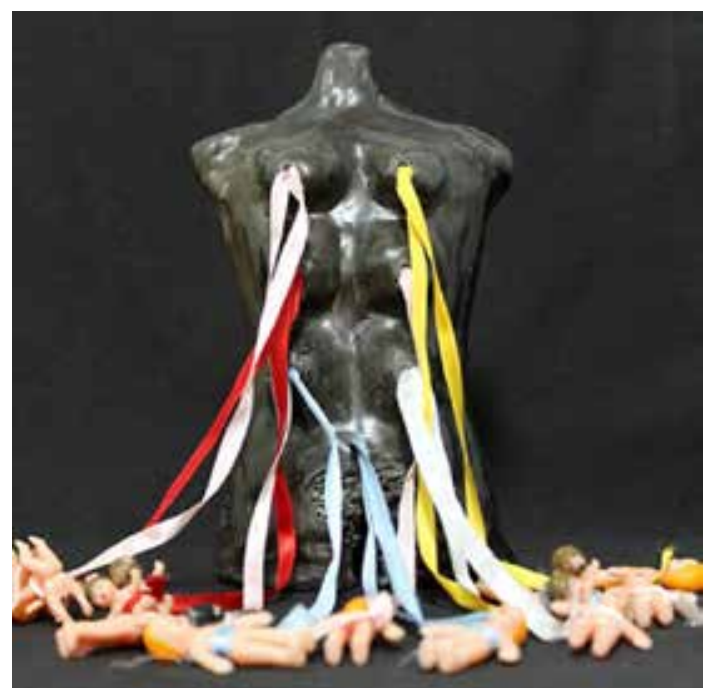

Fonte: Rosana Paulino, Ama de Leite (2005)Disponivel em <http:// www.buala.org/pt/cara-a-cara/atlantico-vermelho-de-rosana-paulino>. 
Imagem 06 - Detalhe da instalação Amas de Leite

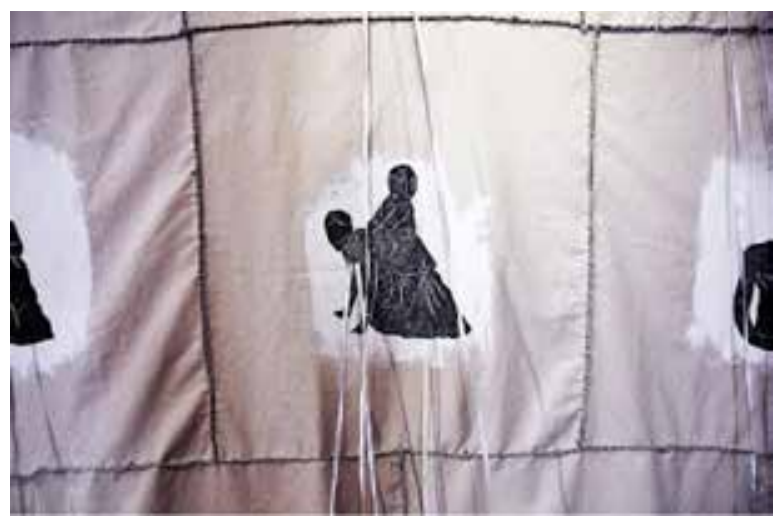

Fonte: Rosana Paulino, detalhe da instalação Amas de Leite (2009) Disponivel em: <http://omenelicksegundoato.blogspot.com/2010/05/mulher-negra-e-artista-estetica-critica.tml>

Quando nos deparamos com esse tipo de obra, claramente politizada e com traços autobiográficos tão fortes de denúncia e revolta, deslocamo-nos para um lugar certamente não estável, o que proporciona olhares diferentes sobre a sociedade e os corpos. Nessa perspectiva, a questão principal desse artigo gira em torno da pergunta: em que medida a obra de Rosana Paulino produziria uma espécie de escuta para as relações sociais?

Segundo Fabris, a arte de Paulino pode ser considerada storyart, isto é, por ela é possivel perceber que história particular e História podem se misturar numa mesma obra de arte; para a autora, Paulino "não é apenas uma artista que reconstrói uma história familiar. É uma artista negra, que desconstrói diferentes estereótipos sociais e estéticos, envolvendo em suas operações questões relativas à raça, à identidade e à sexualidade" (FABRIS, 1999, p. 73).

Para Oliveira (2012), cada vez mais seu trabalho artístico vai revelando um aspecto narrativo e autobiográfico, de modo que suas raízes vão ficando mais evidentes. Carregadas desse tipo de narrativa pessoal, como é o caso de Paulino, tais imagens assumem uma forma de resistência contra o esquecimento da nossa História:

A leitura pessoal das memórias se contrapõe à amnésia e a a patia que o oferecimento frequente de informações acarreta na cultura atual. Nesse contexto, surgem criações plásticas impregnadas de africanidade ou que valorizam uma poética afrobrasileira (pertencente a artistas negros e não-negros) que se valendo dos signos, cores, materiais e motivos da tradição africana criam novos léxicos. (OLIVEIRA, 2012, p. 37). 


\section{Parede da Memória e Tecido Social}

Em Parede da Memória (1994) também podemos perceber essa ancestralidade, pois consiste em um mural em que Paulino coloca fotos de seus familiares em patuás, como se fosse uma árvore genealógica, uma busca pela sua identidade. Como ela própria explicou: "Parede da Memória tem a propriedade de ligar, não apenas simbólica, mas também fisicamente, os componentes da família e das origens das quais derivo" (PAULINO, 2011, p. 25).

Essa tentativa de resgatar uma herança cultural é de suma importância para os afrodescendentes, pois, como bem lembra Oliveira (2012), a diáspora dos negros fez com que laços familiares se fragmentassem a ponto de que essa ancestralidade pudesse se perder com o decorrer do tempo, e é por isso que essa retomada da história dos negros por meio das artes visuais se faz tão significativa, em seu valor estético, mas sobretudo social e histórico.

Imagem 07 - Parede de Memória, 1994. Rosana Paulino. Serigrafia em almofadas, $8 \times 8 \times 3 \mathrm{~cm}$

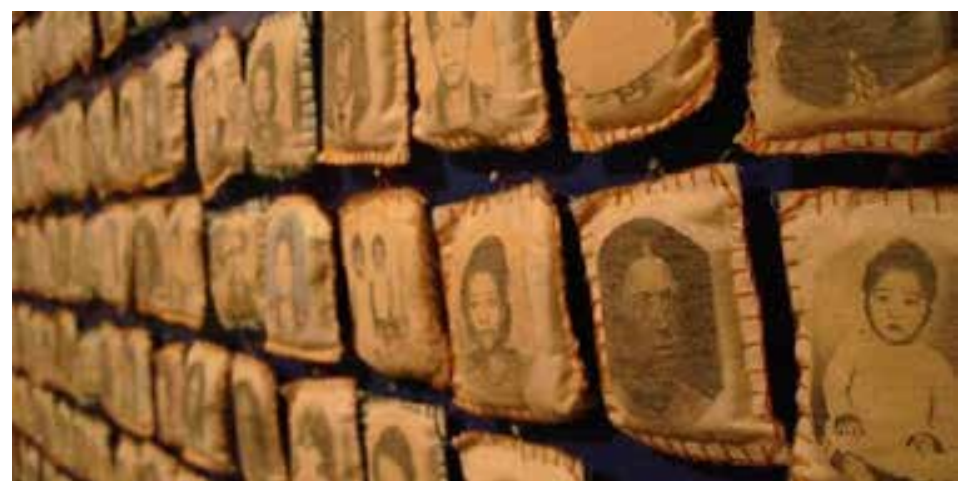

Fonte: Rosana Paulino, Parede de Memória (1994) Disponivel em <http://cean2d.blogspot.com/2012/08/parede-de-memoria-1994-rosana-paulino.html>.

Outra obra de Paulino em que há preferência pelo uso da costura como em Bastidores e Parede da Memória, é Tecido Social, peça na qual a artista se utiliza de um termo da Sociologia para tratar sobre a vida das pessoas imersas no caos das grandes cidades. Ai, Paulino procurou mostrar os "amontoados humanos" que surgem em grandes metrópoles, como eles conseguem sobreviver em pequenos espaços urbanos e que a relação entre eles é conflituosa: quando incomodam, "são removidos pelo poder público até brotar em outro ponto, e depois outro, e outro... Por vezes o amontoado permanece e muda as características da cidade, criando novas fronteiras, novas relações, novos embates" (PAULINO, 2011, p. 
27). A costura na peça, assim como em Bastidores, é malfeita e forçada, de tal modo que o que poderia representar acordo ou conexão entre os grupos humanos acaba por significar repressão e agressividade.

Imagem 08 - Tecido Social. Monotipia colorida e costura sobre tecido. Aproximadamente 2,80 ×5,00m. 2010.

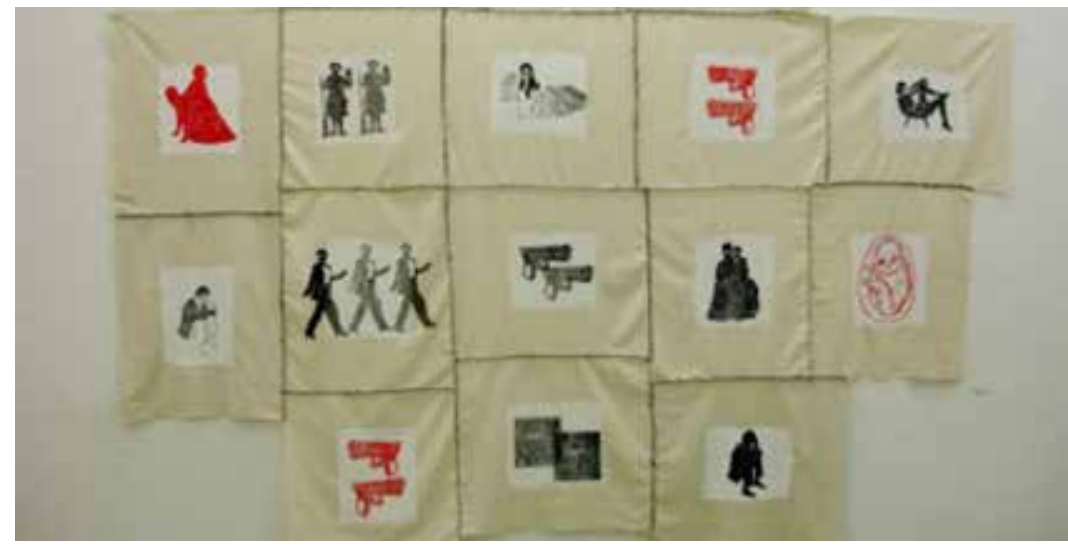

Fonte: Rosana Paulino, Tecido Social (2010) Disponivel em <http://www.rosanapaulino.com.br/blog/2010/06/>.

Em sua tese, Paulino (2011) comenta sobre o cerzido dessa obra, apontando que a costura deveria estar do avesso, mas que optou por trazê-la à frente para demonstrar a ideia de um tecido social feito de retalhos antagônicos em que partes opostas são suturadas em um mesmo corpo social, como paradoxos costurados uma cultura erudita e uma cultura popular, a inclusão e a exclusão etc. Junto dessa peça, há outras duas monotipias que seguem a mesma linha de criação: Babel e Corrida, nas quais a artista indica ter usado personagens vendados para representar a dificuldade da sociedade em procurar uma reparação perante os erros que foram cometidos com as mulheres negras e os negros no decorrer da História.

\section{As três graças}

Já Sem Título (para as Três Graças), de 1998, consiste em mechas de cabelos enrolados postos em bastidores de costura, com nomes femininos escritos embaixo, e no meio da peça surge um furo, um círculo rasgado e anônimo. Essa obra chama atenção por sua delicadeza, já que faz alusão a um relicário de fios de cabelo; não obstante, ela nos remete também a uma massificação, pois, apesar dos nomes distintos escritos embaixo, as mechas de cabelo estão idênticas, em série, como forma de reduzir aqueles nomes, isto é, aquelas pessoas, a sua anatomia, ao seu cabelo crespo. Trata-se de uma maneira de nos mostrar como 
as mulheres negras são reduzidas a uma imagem e aos cabelos que não estão de acordo com o padrão de beleza ocidental.

Imagem 09 - Sem título (para as Três Graças) - 75.5 x 57 cm - 1998

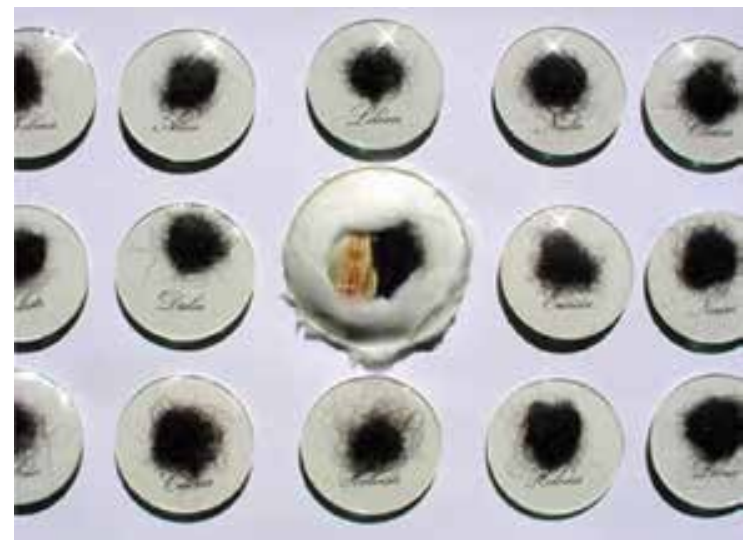

Fonte: Rosana Paulino, Sem título (para as Três Graças) (1998). Disponivel em: <https://fissuraa.wordpress.com/2012/04/08/rosana-paulino/>.

O título faz referência à tela "As três graças" (1505) de Rafael de Sanzio, na qual três deusas da mitologia grega são representadas como símbolo de harmonia e beleza. Paulino utilizou esse título para ironizar a busca por uma beleza idealizada como a dessas três deusas, um tipo de beleza que não abarca a diversidade de corpos femininos que existem.

A respeito deste trabalho, Bordo (1997, p. 19) remete-se a Foucault e Bourdieu para evidenciar que o corpo é um "lugar prático direto de controle social". Esse controle aparece em momentos triviais do nosso dia-a-dia, em atividades que se tornam automáticas e é assim que surge um corpo dócil, regulado segundo normas culturais, mesmo que conscientemente $\circ$ indivíduo acredite possuir alguma autonomia. No caso da obra de Paulino, podemos perceber que a artista procura mostrar que um ideal de beleza já imposto é de antemão uma forma de controle do corpo (feminino), e um exemplo disso são as práticas em que mulheres procuram de toda forma alcançar um tipo de aparência que corresponda ao padrão cultural vigente seja através de dietas extremistas, cirurgias corporais ou alisamento de seus cabelos e daí por diante.

Através da busca de um ideal de feminidade evanescente, homogeneizante, sempre em mutação - uma busca sem fim e sem descanso, que exige das mulheres que sigam constantemente mudanças insignificantes e muitas vezes extravagantes da moda - os corpos femininos tornam-se o que Foucault chama de "corpos dóceis": 
aqueles cujas forças e energias estão habituadas ao controle externo, à sujeição, à transformação e ao "aperfeiçoamento".' Por meio de disciplinas rigorosas e reguladoras sobre a dieta, a maquiagem, e o vestuário - princípios organizadores centrais do tempo e do espaço nos dias de muitas mulheres - somos convertidas em pessoas menos orientadas para o social e mais centradas na automodificação. (BORDO, 1997, p. 20).

De modo geral, Paulino (1997) mostra como há uma imposição perversa de padrões que excluem de forma contundente a beleza afro. Em uma entrevista ao curador e crítico de arte Fernando Cocchiarale (1997), Paulino afirma que em seu processo criativo procura utilizar objetos do cotidiano que são pouco valorizados, apropriando-se daquilo que não é desejado ou bem visto. Sobre esta obra em particular, a artista escreve:

Cabelo "ruim", "pixaim", "duro". Cabelo que dá nó. Cabelos longe da maciez da seda, longe dos comerciais de shampoo. Cabelos de negra. Cabelos desvalorizados. Cabelos vistos aqui como elementos classificatórios, que distinguem entre o bom e o ruim, o bonito e o feio [...] Pensar em minha condição no mundo por intermédio do meu trabalho. Pensar sobre as questões de ser mulher, sobre as questões da minha origem, gravadas na cor da minha pele, na forma dos meus cabelos. (PAULINO, 1997, p. 114).

Nesta mesma entrevista, Paulino opina que o processo de fazer arte sempre deve ser sincero, isto é, deve estar relacionado a algo que toque o artista profundamente, pois, desse modo, isso refletirá em sua obra, seja de forma mais evidente ou por meio da escolha de uma determinada cor, por exemplo. No caso de Paulino, é sua condição no mundo que lhe traz material para suas peças, assim pontuando questões importantes acerca de sua própria "condição de mulher e negra. Olhar no espelho e me localizar em um mundo que muitas vezes se mostra preconceituoso e hostil é um desafio diário" (PAULINO, 1997, p. 114) desafio que the serve como inspiração para criar obras que abordam o racismo e a condição da mulher negra no espaço público e privado.

\section{É tão fácil ser feliz?}

Essa obra, de 1995, também traz o debate sobre o corpo da mulher nos diferentes espaços. A peça mostra três imagens, em seu topo está a frase "é tão fácil ser feliz" e abaixo a fotografia de uma menina negra, vestida de branco e de costas para um espelho; junto a essa há a gravura de uma mulher vestida de noiva e outra com um traje formal, usado, normalmente, em um ambiente de trabalho. 
Imagem 10 - É Tão Fácil Ser Feliz, 1995, imagem transferida e matriz de acetato sobre papel, $62 \times 45 \mathrm{~cm}$

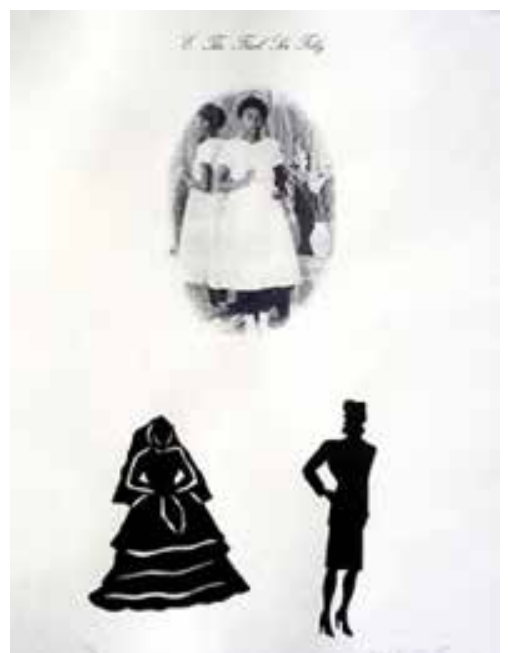

Fonte: Rosana Paulino, É Tão Fácil Ser Feliz (1995) Disponivel em <http://www.rosanapaulino.com.br/blog/galeria/>.

Paulino (1997) parece sugerir que a felicidade da jovem estaria limitada entre optar pelo casamento ou pela vida profissional? Pelo sim e pelo não, a escolha não é simples e fácil tal como indica o nome da obra. Ora, optar por uma vida a dois, isto é, "em família", ou obter sucesso profissional é algo que atormenta o imaginário feminino há um bom tempo. Além disso, é preciso levar em conta que em ambos estes espaços, normalmente, há a dominação da figura masculina. Como propõe Tvardovskas (2012, p. 252):

em nenhuma das saídas parece haver a tão valorizada e desejada felicidade: por um lado, o casamento introduz o receio do confinamento espiritual e físico através da submissão ao marido; por outro, as limitadas oportunidades de trabalho jogam para escanteio as possibilidades de autorrealização.

A autora também nos lembra que essa felicidade, tão proclamada pelo sistema capitalista e difundida como consumismo desenfreado, se torna ainda mais distante quando se trata de uma mulher negra e pobre que, por sua condição de desvantagem, possui pouquíssima escolha: ela precisa trabalhar e se contentar com um salário que não sustenta uma família, tendo que aguentar, diversas vezes, uma dupla ou tripla jornada de trabalho, sobretudo nos casos das mães solteiras. Estas são dificuldades que muitas das mulheres negras e pobres se deparam todos os dias, batalhas em que o que está em jogo é sua imagem, sua vida e seus desejos. 
Tal como grande parte de suas obras, com essa Paulino faz ver como o estereótipo da mulher negra, que paira no imaginário social, possa ser desmontado, dando assim espaço para corpos com história, marcados por uma herança de luta. Podese mesmo afirmar que os seus trabalhos:

\begin{abstract}
Desvinculam a experiência carnal das mulheres do regime visual masculino e explicitam corpos carregados de traumas e de rejeições: a autoimagem que não é aceita (por outros, mas também por si mesma), a sexualidade que é explorada, o trabalho mal remunerado etc.. (TVARDOVSKAS, 2012, p. 253).
\end{abstract}

\title{
Penélope contemporânea
}

Como toda obra de arte strictu sensu, as obras de Paulino alcançam uma dimensão ética, propriamente dita, e se apresenta como disparadora de questionamentos acerca da condição da mulher e dos negros, antes e hoje. Ela ataca situações de vulnerabilidade estruturais da sociedade brasileira, de tal modo que certas discussões, já adormecidas, quase que recalcadas no cenário social, ressurgem carregadas de afeto em suas instalações, gravuras, fotografias.

Em sua tese, Paulino (2011) afirma que na elaboração de suas obras, principalmente nas peças em que há fitas, linhas, tecidos, ela se sente como uma Penélope contemporânea. A artista se debruça sobre sua história e suas angústias através de seu trabalho, cruzando fios, resgatando sua ancestralidade, fazendo de seu tecer uma maneira de se posicionar no mundo. Há uma busca por um devir que traga consigo vestígios de momentos passados, tal como lemos em suas palavras: "como as aulas de costura e artesanato tidas na infância e que, neste momento, passam a ter um sentido totalmente diverso desvelando um universo escondido no mais profundo de mim" (PAULINHO, 2011, p.25).

Sua poética visual é uma forma de contestar a subjetividade mercadológica, capitalística; é, em suma, uma maneira de resistir ao empobrecimento político e subjetivo que aparece como sintoma incurável de nossa época.

O que há é simplesmente uma produção de subjetividade. Não somente uma produção da subjetividade individuada - subjetividade dos indivíduos - mas uma produção de subjetividade social, uma produção da subjetividade que se pode encontrar em todos os níveis da produção e do consumo. E mais ainda: uma produção da subjetividade inconsciente. A meu ver, essa grande fábrica, essa grande máquina capitalística produz inclusive aquilo que acontece conosco quando sonhamos, quando devaneamos, quando fantasiamos, quando nos apaixonamos e assim por diante. Em todo caso, ela pretende garantir uma função hegemônica em todos esses campos. (GUATTARI \& ROLNIK, 1996, p.16). 
Em resumo, o que pretendemos trazer com este ensaio foi revelar a inquietação que as obras de Paulino podem trazer ao circuito da arte contemporânea. Suas experimentações fazem emergir um questionamento rigoroso sobre os modos de construção das subjetividades e, com isso, a artista acabou por nortear sua própria vida de forma mais criativa. Como propõe Tvardovskas (2010), perdeuse a necessidade de afirmar uma identidade do artista; Paulino toma a si mesma como uma obra de arte, isto é, há um "viver artista" que proporciona uma dimensão ética e política na produção de sua arte. Suas obras também podem ser compreendidas, enfim, como modo de ressignificar a dor das mulheres negras, uma maneira de não esquecer o sofrimento vivido, mas de também produzir novas sensações com isso, retomar a ancestralidade afro e toda história que a permeia.

\section{Referências}

BORDO, Susan R. O corpo e a reprodução da feminidade: uma apropriação feminista de Foucault. Gênero, corpo, conhecimento. Rio de Janeiro, RJ: Rosa dos Tempos, 1997.

BUTLER, Judith. Problemas de Gênero: Feminismo e Subversão da Identidade. Tradução Renato Aguiar. Rio de Janeiro: Civilização Brasileira, 2003.

CANTON, Katia. Novíssima arte brasileira: um guia de tendências. São Paulo: lluminuras, 2001.

CARVALHO, Vania Carneiro de.Gênero e Artefato. $O$ sistema doméstico na perspectiva da cultura material - São Paulo, 1870-1920. São Paulo: EDUSP/ FAPESP, 2008.

COCCHIARALE, Fernando. Entrevista de Rosana Paulino. Panorama de arte atual brasileira/97. Texto crítico Tadeu Chiarelli; comentário Rejane Cintrão; apresentação Milú Villela. São Paulo: MAM, 1997.

DELEUZE, Gilles. Conversações, 1972-1990. São Paulo : Editora 34, 1992.

DELEUZE, Gilles ; GUATTARI, Félix. Mil Platôs: capitalismo e esquizofrenia, vol. 4. São Paulo: Editora 34, 1997.

DIDI-HUBERMAN, Georges. O que vemos, o que nos olha. São Paulo, Ed. 34, 1998. 
DIONÍSIO, Gustavo Henrique. A carne é fraca? Violência e ironia, psicanálise e arte contemporânea. Psicologia Argumento, v. 34, n. 86, 2016.

FABRIS, Annateresa. Percorrendo veredas: hipóteses sobre a arte brasileira atual. Revista USP, n. 40, p. 68-77, 1999.

FAZZOLARI, Cláudia. Da estratégia ficcional/da poética visual para o gênero feminino na contemporaneidade : Carmen Calvo, Rosângela Rennó, Rosana Paulino e Ana Prada, In: Anais do Seminário Internacional Fazendo Gênero 7, UFSC, Florianópolis, ago. 2006. Disponivel em: <http://www.fazendogenero. ufsc.br/7/artigos/C/Claudia_Fazzolari_35.pdf>. Acesso 27 de novembro/2015.

GUATTARI, Félix \& ROLNIK, Suely. Micropolítica: cartografias do desejo. Petrópolis: Vozes, 1996.

OLIVEIRA, Alecsandra Matias de et al. Memória da Pele: O Devir da Arte Contemporânea Afro-Brasileira. Arte e Cultura da América Latina, v. 25, 2012.

PAULINO, Rosana. Imagens de sombras, Tese (Doutorado em Artes Visuais) - Escola de Comunicação e Artes, Universidade de São Paulo, São Paulo, 2011.

RECKITT, Helena e PHELAN, Peggy. Art and Feminism. Nova lorque: Phaidon, 2006. Revista Estudos Feministas - Vol. 3, No 2 (1995) - Dossiê Mulheres Negras.

ROLNIK, Suely. Pensamento, corpo e devir: uma perspectiva ético/estético/ política no trabalho acadêmico. Cadernos de subjetividade, v. 1, n. 2, p. 241-251, 1993.

Desentranhando futuros. Com Ciência, n. 99, 2008.

SAMPAIO, Cláudiaĺngrid Campos Paiva Moreira. Discussão étnico racial sobre as artes visuais brasileiras: Rosana Paulino, Paulo Nazareth, Jaime Lauriano e - discurso do artista negro na contemporaneidade. Anais do XXV Congresso Nacional da Federação dos Arte-educadores do Brasil , v. 25, 2015.

SCOTT, Joan W. et al. Os usos e abusos do gênero. Projeto História. Revista do Programa de Estudos Pós-Graduados de História, v. 45, 2012.

TRIZOLI, Talita. O Feminismo e a Arte Contemporânea-Considerações. Anais do $17^{\circ}$ Encontro Nacional da Associação Nacional de Pesquisadores em Artes 
Plásticas Panorama da Pesquisa em Artes Visuais, v. 17, 2008.

TVARDOVSKAS, Luana Saturnino. Tramas feministas na arte contemporânea brasileira e argentina: Rosana Paulino e Claudia Contreras, 2013.

Rosana Paulino:" É tão fácil ser feliz". Revista Gênero, v. 10, n. 2, 2012.

Modos de viver artista: Ana Miguel, Rosana Paulino e Cristina Salgado. Revista Aulas. Dossiê Estéticas da Existência, Campinas, n. 7, p. 59-96, 2010.

ULPIANO, Claudio. [Aula] A Idéia de Perfeição (1989), Disponivel em: <http:// claudioulpiano.org.br.s87743.gridserver.com/?p=84\&print=1>. Acesso em 06 de dezembro /2015.

Recebido em março de 2017

Aprovado em outubro de 2018 